\title{
Coronary sinus type atrial septal defect in a child with pulmonary atresia and Ebstein's anomaly
}

\author{
G A RUSSELL, P G I STOVIN \\ From the Department of Morbid Anatomy and Histopathology, Addenbrooke's Hospital, Cambridge
}

SUMMARY At birth an infant was found to have an unusual series of abnormalities with a coronary sinus type atrial septal defect complicating pulmonary atresia with an intact ventricular septum and Ebstein's anomaly. The functionally important anomalies were diagnosed by echocardiography and cardiac catheterisation. The coronary sinus defect and Ebstein's anomaly were detected only at necropsy. Although only a single case, the features of this heart favour Bull's revised classification of pulmonary atresia.

Communication of the coronary sinus with both atria is a very rare congenital abnormality. We report a case occurring in a female infant with an unusual combination of pulmonary atresia and Ebstein's anomaly of the tricuspid valve. We also review the range of coronary sinus type atrial septal defects found in published reports and discuss problems in the classification of pulmonary atresia.

\section{Case report}

A girl weighing $4.6 \mathrm{~kg}$ was born at the maternity unit at this hospital. Her mother, aged 30 years, had had an uneventful pregnancy and labour was spontaneous at 40 weeks' gestation. Soon after delivery the infant became deeply cyanosed on crying. Examination showed a loud pansystolic murmur down the left sternal edge. Her arterial oxygen pressure $\left(\mathrm{PO}_{2}\right)$ was $5 \cdot 2$ $\mathrm{kPa}$ and remained unaltered in $95 \%$ oxygen. She was transferred to the Hospital for Sick Children, Great Ormond Street, London, where cardiac catheterisation and cross sectional echocardiography were performed. These showed complete atresia of the pulmonary valve with an intact ventricular septum, an atrial septal defect, right ventricular hypertrophy, a small tricuspid valve, and persistent ductus arteriosus. The following day she underwent surgery and had a Blalock-Taussig shunt sutured between the right pulmonary artery and the brachiocephalic artery; her subclavian artery was deemed too small to permit this

Requests for reprints to Dr G Russell, Department of Morbid Anatomy and Histopathology, The John Bonnett Clinical Laboratories, Addenbrooke's Hospital, Cambridge CB2 2QQ. more usual site of anastomosis to be used.

She had an eventful postoperative course complicated by a right diaphragmatic palsy, empyema, prolonged artificial ventilation, and pneumothorax. She died at 13 weeks old after a cardiac arrest.

\section{NECROPSY FINDINGS}

The heart was enlarged. A fenestrated ostium secundum type atrial septal defect was found. Another communication between the atria was present at the site of the coronary sinus. A probe could be guided into both atria and into the coronary sinus through this defect (Fig. la). The coronary sinus itself was dilated. No left superior vena cava was present. The right atrium was dilated. The tricuspid valve was displaced apically by about $1 \mathrm{~cm}$ from the annulus fibrosus at the septal leaflet. The anterior leaflet was not as severely affected. The valve leaflets were thickened and attached to diminutive chordae and papillary muscles. The valve orifice was restrictive with a diameter of only $0.4 \mathrm{~cm}$. The endocardial surface between the valve orifice and the annulus had an "atrialised" appearance. The septal area of atrialised ventricle contained a blind ending pit where the fibrous tissue adherent to the ventricular muscle swept into the origin of the pulmonary infundibulum (Fig. 1b). The right ventricular cavity itself was very small and the trabecular portion virtually obliterated. Several dilated vascular channels were found in the right ventricular wall. One of these could be traced to the cavity of the right ventricle, although no communication with the coronary arteries could be found. The wall of the right ventricle was hypertrophied (1.4 $\mathrm{cm}$ thick) and had a fihrous texture $A$ thin torminus 

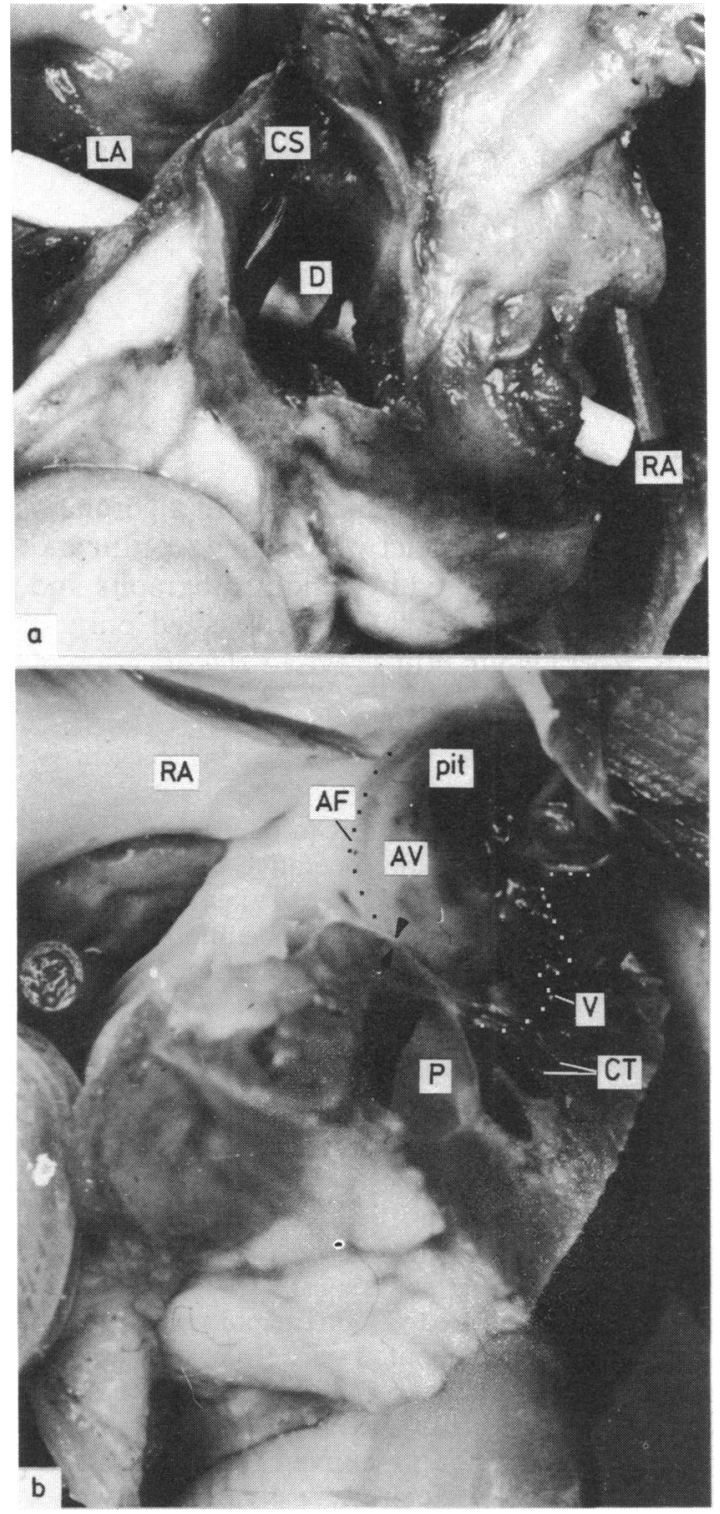

Fig. 1 (a) Necropsy specimen showing the opened coronary sinus (CS) viewed across the atrial septum. The white probe passed easily from the right atrium $(R A)$ to the left atrium $(L A)$ along the coronary sinus and is visible through the defect $(D)$ in the anterior wall of the sinus. (b) Necropsy specimen showing Ebstein's anomaly of the tricuspid value. The lumen of the valve (V) is displaced apically. Leaflet material is adherent to the myocardium covering the atrialised ventricle (AV) between the annulus fibrosus $(A F)$ and the valve orifice and is visible as a thin line between the two arrow heads. A blind ending pit is formed by leaflet material lining the origin of the pulmonary infundibulum. Diminutive chordae tendineae (CT) and papillary muscles $(P)$ are present. pulmonary infundibulum ended $1 \mathrm{~mm}$ below the pulmonary valve. The valve itself was atretic with fusion along the lines of cusp apposition to produce a triradiate raphe appearance. The left sided structures appeared relatively normal except for moderate left ventricular hypertrophy $(1.1 \mathrm{~cm}$ thick) and dilatation of the aortic root. The coronary arteries and coronary ostia were normal. The ductus arteriosus was patent.

Microscopical examination of the heart showed an endocardial fibroelastosis of the right ventricle but not the left. Dilated vascular channels were present in the right ventricular wall draining the cavity of the ventricle. The myocardial cells of the right ventricle were thin and attenuated, while other areas showed cells with unusually large nuclei perhaps representing a response to the raised intraventricular pressure. The right coronary arterial system showed pronounced fibrointimal proliferation, probably reflecting increased pressure in the arteries.

\section{Discussion}

This patient's heart presented a very rare combination of individually rare abnormalities. Mantini and coworkers have comprehensively described the range of anomalies affecting the coronary sinus. ${ }^{1}$ Communication of the atria via the coronary sinus has been reviewed by Cohle et al. ${ }^{2}$ They found eight cases in published reports and added one more. Three of these were incidental findings at postmortem examination. Three cases had evidence of functional left to right shunting through the defect. Three cases described by Rose et al had evidence of a congenital obstructive lesion in the heart; one had mitral atresia, one tricuspid atresia, and one stenosis of the orifice of the coronary sinus in the right atrium. ${ }^{3}$ No cases of this type of anomaly occurring concurrently with another atrial

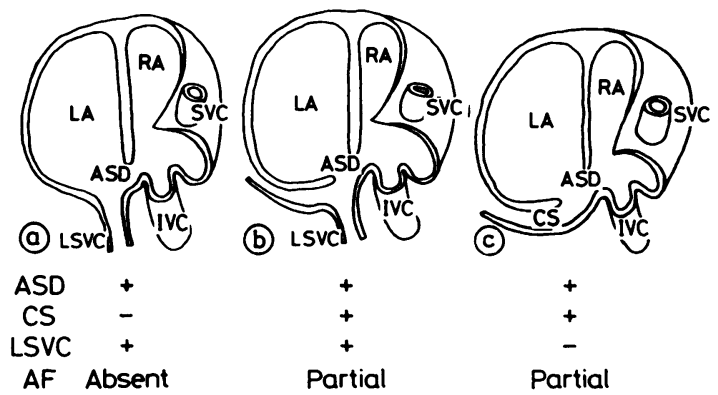

Fig. 2 Diagrams showing patterns of atrial septal defects involving the coronary sinus: (a) Raghib et al4; (b) Rose et al 3 ; (c) present case, also Cohle et al ${ }^{2}$ and Mantini et al. ${ }^{1} A S D$, atrial septal defect; $A F$, atriovenous fold; $C S$, coronary sinus; LSVC, left superior vena cava; SVC, superior vena cava; IVC, inferior vena cava; $L A$, left atrium; $R A$, right atrium. 
septal defect were described. Our case is unique, therefore, in having the two forms of atrial septal defect complicating pulmonary atresia together with Ebstein's anomaly.

Another pattern of coronary sinus defect has been described by Raghib et al, who found a persistent left superior vena cava associated with an absent coronary sinus. ${ }^{4}$ These abnormalities probably represent a spectrum of maldevelopment of the left horn of the sinus venosus and left common cardinal vein. The sinus venosus is normally partitioned from the left atrium by the left atriovenous fold. Cohle $e t$ al point out that failure of development of the atriovenous fold would lead to communication of the coronary sinus with the left atrium and an atrial septal defect at the coronary sinus ostium ${ }^{2}$ (Fig. 2).

Pulmonary atresia is usually classified into two types. ${ }^{5}$ The morphology of the right ventricle is used as the determinant of the type of lesion present. The type I lesion is associated with a small right ventricular cavity and hypertrophy of its wall. The tricuspid valve is said to be hypoplastic but usually competent. Aberrant intramyocardial sinusoids are often found in the right ventricular wall. These vessels may link the cavity with epicardial branches of the coronary arteries. ${ }^{6}$ The type II pattern is found with an incompetent valve and has a normal or dilated right ventricle.

The lesions in this heart present problems in classification. The tricuspid valve in Ebstein's anomaly is usually incompetent. When Ebstein's anomaly has been found with pulmonary atresia usually the type II pattern has been described. ${ }^{57}$ Zuberbuhler and Anderson, however, showed in their 10 cases of pulmonary atresia with intact ventricular septum and Ebstein's anomaly that when the tricuspid valve was restrictive or dysplastic there was an associated hypoplasia of the right ventricular cavity ${ }^{8}$ Although the right ventricular cavity in this case was deceptively small because of the low set tricuspid orifice, nevertheless the hypertrophy of the wall and the presence of intramyocardial sinusoids suggest that this is a type I lesion in the presence of Ebstein's anomaly.

Bull $e t$ al have proposed a revised classification of pulmonary atresia with intact ventricular septum which places less emphasis on the competence of the tricuspid valve but more on the diameter of its orifice. ${ }^{9}$ Their work showed that the diameter of the tricuspid valve decreased with the severity of the ventricular abnormality as assessed by a "tripartite" analysis of the right ventricular morphology. This scheme of classification would accommodate the abnormalities of this heart better than the previous system. The diminutive tricuspid valve orifice in this heart matched the severe right ventricular hypoplasia with absent trabecular portion.

We thank Dr Ashley King for her help and Mr C Burton for the photography.

\section{References}

1 Mantini E, Grondin CM, Lillehei CW, Edwards JE. Congenital anomalies involving the coronary sinus. Circulation 1966; 33: 317-27.

2 Cohle SD, Titus JL, Kim H-S, Erikson E. Communication of the coronary sinus with both atria. Arch Pathol Lab Med 1981; 105: 40?-8.

3 Rose AG, Beckman CB, Edwards JE. Communication between coronary sinus and left atrium. Br Heart $\mathcal{F}$ 1974; 36: 182-5.

4 Raghib G, Ruttenberg HD, Anderson RC, Amplatz K, Adams $\mathbf{P}$ Jr, Edwards JE. Termination of left superior vena cava in left atrium, atrial septal defect, and absence of coronary sinus. Circulation 1965; 31: 906-18.

5 Davignon AL, Greenwold WE, Dushane JW, Edwards JE. Congenital pulmonary atresia with intact ventricular septum, clinicopathologic correlation of two anatomic types. Am Heart f 1961; 62: 591-602.

6 Williams RR, Kent GB Jr, Edwards JE. Anomalous cardiac blood vessel communicating with the right ventricle. Arch Pathol 1951; 52: 480-7.

7 Freedom RM, Dische MR, Rowe RD. The tricuspid valve in pulmonary atresia and intact ventricular septum. Arch Pathol Lab Med 1978; 102: 28-31.

8 Zuberbuhler JR, Anderson RH. Morphological variations in pulmonary atresia with intact ventricular septum. Br Heart $\mathcal{A}$ 1979; 41: 281-8.

9 Bull C, de Leval MR, Mercanti C, Macartney FJ, Anderson RH. Pulmonary atresia and intact ventricular septum: a revised classification. Circulation 1982; 66: 26672 . 